\title{
New species of Paraodontomma from mid-Cretaceous Burmese amber with muscle tissue preservation (Coleoptera: Archostemata: Ommatidae)
}

\author{
Yan-Da Li ${ }^{1,4}$; Shûhei Yamamoto ${ }^{2,5}$; Di-Ying Huang ${ }^{1,6}$ \& Chen-Yang Cai ${ }^{1,3}, 7$ \\ ${ }^{1}$ Chinese Academy of Sciences, Nanjing Institute of Geology and Palaeontology, Center for Excellence in Life and Paleoenvironment, \\ State Key Laboratory of Palaeobiology and Stratigraphy. Nánjīng, Jiangsu, China. \\ 2 Hokkaido University, Hokkaido University Museum. Sapporo, Hokkaidō, Japan. \\ ${ }^{3}$ University of Bristol, School of Earth Sciences. Bristol, United Kingdom. \\ ${ }^{4}$ ORCID: http://orcid.org/0000-0002-9439-202X. E-mail: ydli@pku.edu.cn \\ ${ }^{5}$ ORCID: http://orcid.org/0000-0002-4162-8457. E-mail: s.yamamot0.64@gmail.com \\ ${ }^{6}$ ORCID: http://orcid.org/0000-0002-5637-4867.E-mail: dyhuang@nigpas.ac.cn \\ 7 ORCID: http://orcid.org/0000-0002-9283-8323. E-mail: cycai@nigpas.ac.cn (corresponding author)
}

\begin{abstract}
The third member of the extinct ommatid genus Paraodontomma is reported from mid-Cretaceous Burmese amber. Our observation confirms the transverse ridges on elytra as a diagnostic character for the genus. Paraodontomma leptocristatum sp. nov. differs from previously reported congeners mainly in head subquadrate and without prominent protuberances, pronotal disc without prominent ridges, elytral ridges indistinct, and teeth along elytral margins not forming a wavy pattern. Musculature is preserved in the newly discovered specimen of $P$. leptocristatum, which further demonstrates the preservation potential and irreplaceable value of amber fossils.
\end{abstract}

Keywords. Archostemata; Ommatidae; Paraodontomma; Burmese amber; Muscle.

\section{INTRODUCTION}

Ommatidae today is a small family in the beetle suborder Archostemata, represented by only three genera in the extant fauna (Hörnschemeyer \& Beutel, 2016; Escalona et al., 2020). Recent transcriptomic analyses placed Ommatidae sister to the monospecific Micromalthidae, rather than of Cupedidae (McKenna et al., 2019), even though the two small families differ dramatically in their adult morphology. In contrast to the very low recent diversity, Ommatidae were much more diverse during the Mesozoic. Numerous fossil genera discovered across Europe and Asia (e.g., Tan \& Ren, 2009) are listed in Kirejtshuk (2020). Among them, Paraodontomma Yamamoto was first reported by Yamamoto (2017) from mid-Cretaceous Burmese amber, represented by the type species $P$. burmiticum. Later Jarzembowski et al. (2018) described the second species in this genus, P. szwedoi. Yamamoto (2017) suggested that Paraodontomma is most similar to Odontomma Ren et al., a brochocolein beetle known from Cretaceous Yixian Formation in China (Ren et al., 2006).
Well preserved muscle tissues have been identified from insects in Eocene/Oligocene Baltic amber (Poinar-Jr. \& Hess, 1982, 1985; Grimaldi et al., 1994; Pohl et al., 2010), Miocene Dominican amber (Henwood, 1992a, b; Grimaldi et al., 1994), and Eocene Oise amber (Van de Kamp et al., 2014) (as discussed in Pohl et al., 2021). Recently, flight muscles were also reported from a wasp in the older Cretaceous Burmese amber (Grimaldi et al., 2019). In earlier studies of internal structures of extinct species, amber pieces with insects were cut open and examined with an electron microscope (SEM or TEM) (e.g., Poinar-Jr. \& Hess, 1982, 1985; Grimaldi et al., 1994). Even though this method revealed exceptional details, even at the subcellular level, the specimens were irreversibly destroyed. The development of micro-computed tomography (micro-CT) offers a great chance to investigate fossils non-destructively. The first nearly complete anatomical reconstruction of an insect fossil was conducted with the strepsipteran Mengea tertiana Grote from Baltic amber (Pohl et al., 2010). Later Van de Kamp et al. (2014) also successfully recovered the brain and flight muscles of a fossil wasp in Oise amber. 
In the present study we report the third species of Paraodontomma from Burmese amber. With the aid of micro-CT, fossilized musculature was discovered inside the beetle, which further demonstrates the potential information content of amber fossils.

\section{MATERIAL AND METHODS}

The holotype of Paraodontomma leptocristatum sp. nov. (Figs. 1-8) studied herein originated from amber mines near Noije Bum $\left(26^{\circ} 20^{\prime} \mathrm{N}, 96^{\circ} 36^{\prime} \mathrm{E}\right)$, Hukawng Valley, Kachin State, northern Myanmar. The specimen is deposited in the Nanjing Institute of Geology and Palaeontology (NIGP), Chinese Academy of Sciences, Nanjing, China. The amber piece was trimmed with a small table saw, ground with emery paper of different grit sizes, and finally polished with polishing powder. The previously published holotype of P. szwedoi (Figs. 9-11; NIGP169926, incorrectly labeled as NIGP130418 in Jarzembowski et al., 2018) was also re-examined for comparison.
Photographs under incident light were taken with a Zeiss Discovery V20 stereo microscope. Widefield fluorescence images were captured with a Zeiss Axio Imager 2 light microscope combined with a fluorescence imaging system. In some cases, the amber pieces were immersed in mineral oil (CAS 8020-83-5). Confocal images were obtained with a Zeiss LSM710 confocal laser scanning microscope, using $488 \mathrm{~nm}$ Argon laser excitation line. Images under incident light and widefield fluorescence were stacked in Helicon Focus 7.0.2 or Zerene Stacker 1.04. Confocal images were stacked with colour coding for depth in ZEN 2.3 (Blue Edition), or without colour coding in Helicon Focus 7.0.2. Microtomographic data were obtained with a Zeiss Xradia 520 Versa 3D X-ray microscope at the micro-CT laboratory of NIGP, and analyzed in VGStudio MAX 3.0. Scanning parameters were as follows: isotropic voxel size, $9.4355 \mu \mathrm{m}$; power, $4 \mathrm{~W}$; acceleration voltage, 50 kV; exposure time, $1.5 \mathrm{~s}$; projections, 2201. Images were further processed in Adobe Photoshop CC to enhance contrast.

The terminology and numeration for muscles of head and thorax follow Beutel et al. (2008) and Friedrich et al. (2009).
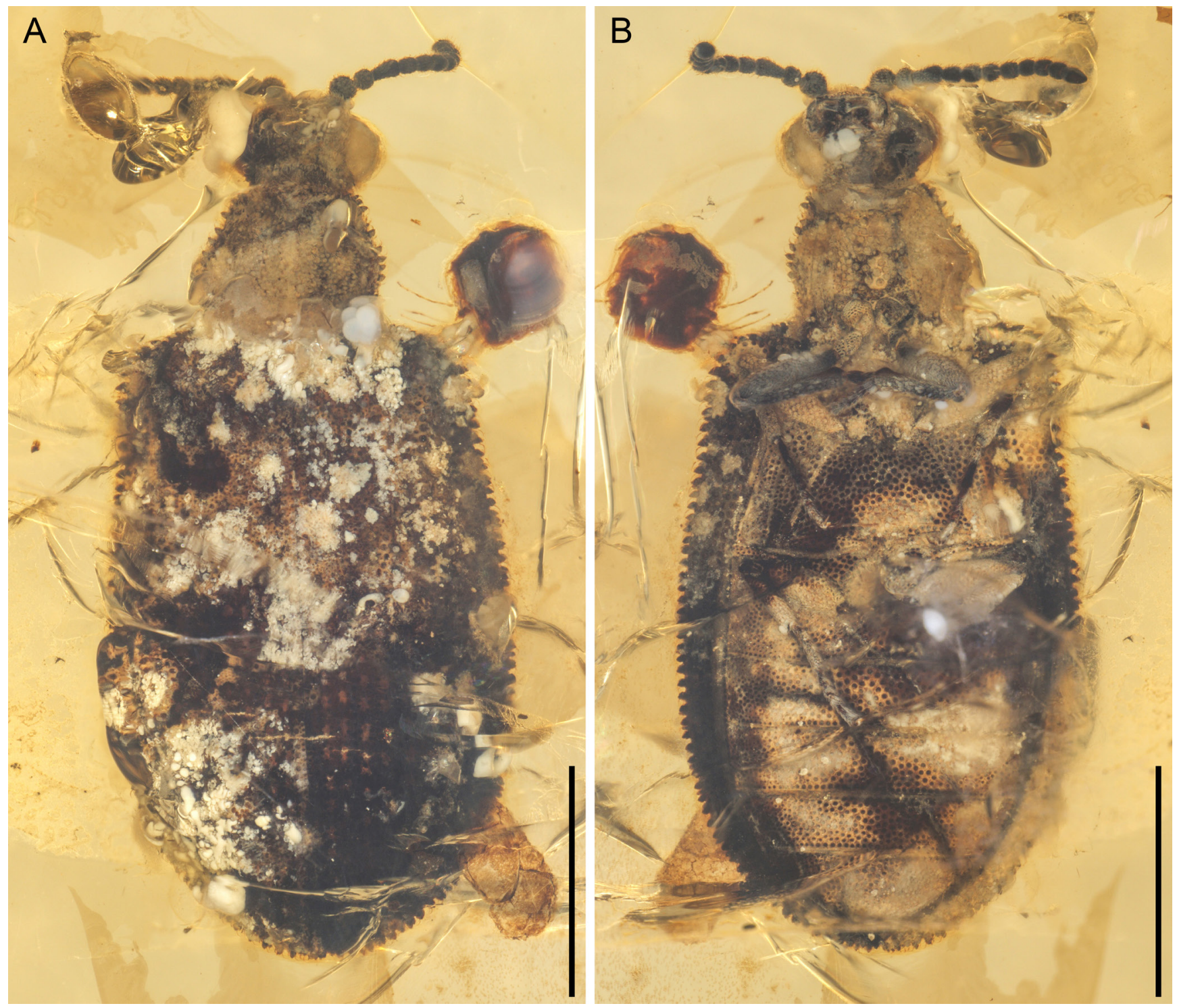

Figure 1. General habitus of Paraodontomma leptocristatum sp. nov., holotype, NIGP174676. (A) Dorsal view. (B) Ventral view. Scale bars: 2 mm. 


\section{RESULTS}

\section{Systematic Paleontology \\ Order Coleoptera Linnaeus, 1758 \\ Suborder Archostemata Kolbe, 1908 \\ Family Ommatidae Sharp \& Muir, 1912 \\ Genus Paraodontomma Yamamoto, 2017}

\section{Paraodontomma leptocristatum Li, Yamamoto \& Cai sp. nov.}

(Figs. 1-8)

Material: Holotype, NIGP174676, adult male, covered with numerous bubbles.
Locality and horizon: Amber mine located near Noije Bum Village, Tanai Township, Myitkyina District, Kachin State, Myanmar; unnamed horizon, mid-Cretaceous, Upper Albian to Lower Cenomanian.

Diagnosis: Head (Figs. 2A, B, 5) subquadrate (elongate in P. burmiticum and P. szwedoi), without prominent posterior protuberances (with prominent protuberances above eyes in P. szwedoi, and also possibly in P. burmiticum; Fig. 10A). Pronotal disc without prominent ridges (Fig. 2C) (with longitudinal ridges in P. szwedoi; Fig. 10C). Elytra with indistinct longitudinal and transverse ridges (Figs. 2F, 6D) (strongly developed in P. burmiticum and
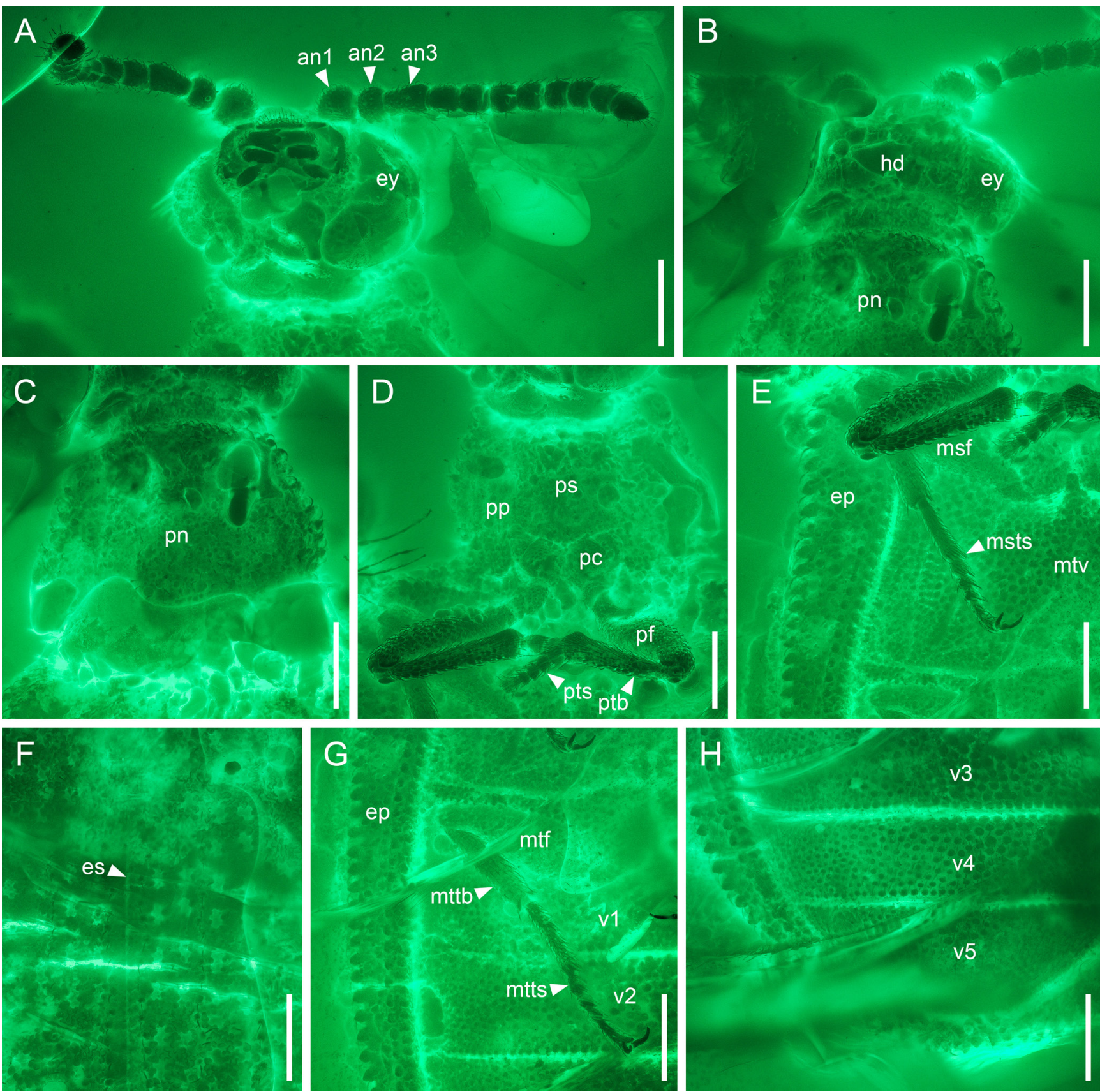

Figure 2. Details of Paraodontomma leptocristatum sp. nov., holotype, NIGP174676, under widefield fluorescence. (A) Head, anteroventral view. (B) Head, posterodorsal view. (C) Prothorax, dorsal view. (D) Prothorax, ventral view. (E) Mid leg and metathorax, ventral view. (F) Elytra, dorsal view. (G) Hind leg, ventral view. (H) Abdominal apex, ventral view. Abbreviations: an1-3 = antennomeres 1-3; ep = epipleuron; es = elytral suture; ey = compound eye; $h d=$ head; $m s f=$ mesofemur; $\mathrm{msts}=$ mesotarsus; $\mathrm{mtf}=$ metafemur; $\mathrm{mttb}=$ metatibia; $\mathrm{mtv}=$ metaventrite; $\mathrm{pc}=$ procoxa; $\mathrm{pf}=$ profemur; $\mathrm{pn}=$ pronotum; $\mathrm{pp}=\mathrm{propleuron} ; \mathrm{ps}=$ prosternum; $\mathrm{ptb}=$ protibia; $\mathrm{pts}=$ protarsus; $\mathrm{v1-5}=$ ventrites $1-5$. Scale bars: $500 \mu \mathrm{m}$. 
P. szwedoi; Fig. 10I). Teeth along outer elytral margins not forming a wave pattern (Figs. 2E, 4D) (wavily arranged in P. burmiticum and P. szwedoi; Figs. 10F, 11C).

Description: Body length about $8.1 \mathrm{~mm}$; maximum width about $3.6 \mathrm{~mm}$ between elytral margins in posterior $1 / 3$ of body. Head and prothorax slender compared to compact unit formed by pterothorax and abdomen; shoulders pronounced. Integument covered with rounded tubercles and setae.
Head (Figs. 2A, B, 5, 6A) prognathous, constricted posteriorly to form a neck (though not well visible on the specimen); maximum width about $1.4 \mathrm{~mm}$ (including eyes); dorsal surface without prominent posterior protuberances. Compound eyes relatively large, protruding laterally. Antennal insertion area located anteriorly, anteromesad anterior margin of compound eyes, separated by more than one but less than two diameters of scapus. Antennal grooves absent on dorsal or ventral side. Postocular temples short.
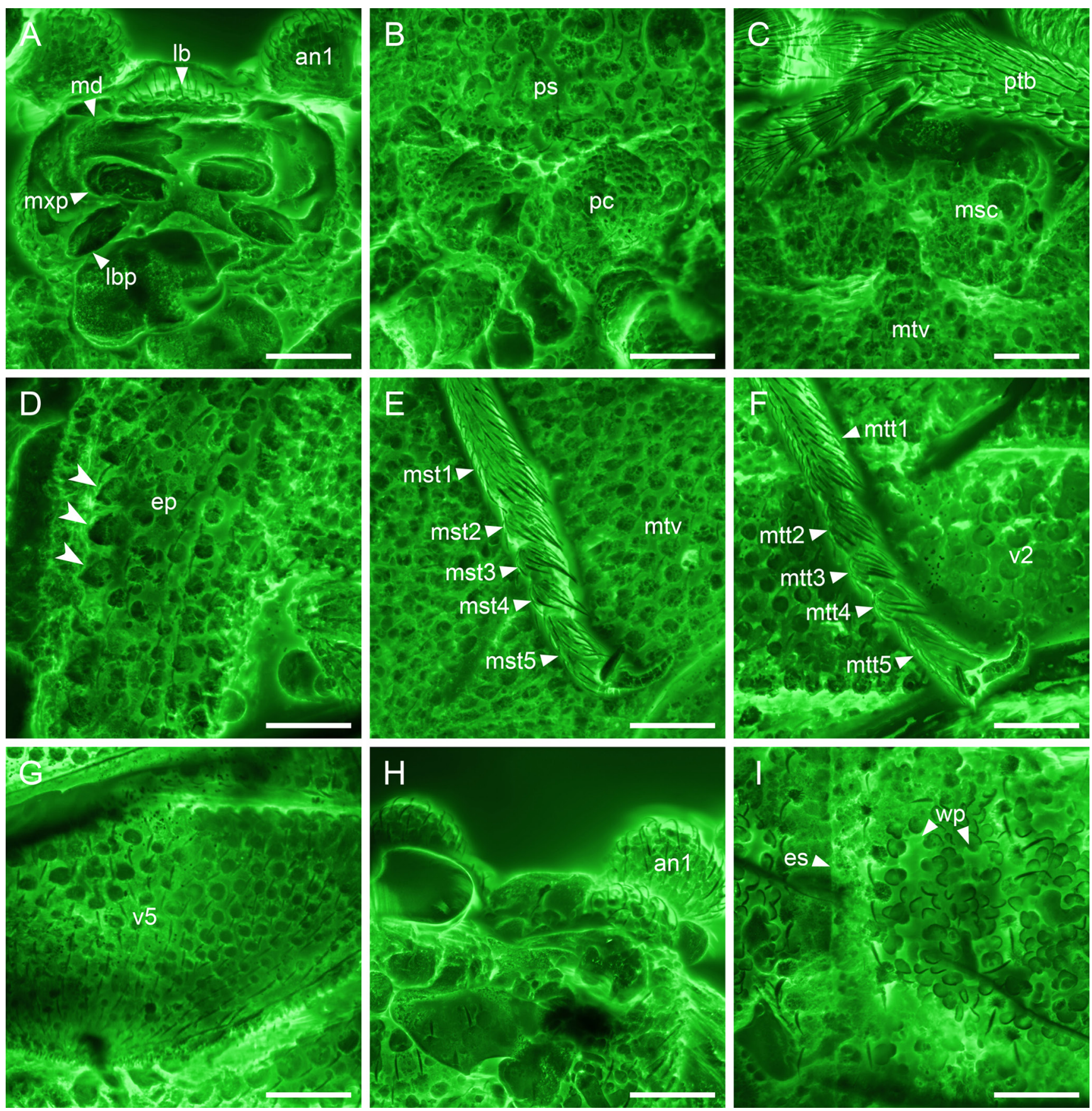

Figure 3. Details of Paraodontomma leptocristatum sp. nov., holotype, NIGP174676, under confocal microscopy. (A) Mouthparts, anterior view. (B) Procoxae, ventral view. (C) Mesocoxae, ventral view. (D) Epipleuron, ventral view, showing the nonwavily arranged teeth along the outer elytral margin (arrowheads). (E) Mesotarsus, ventral view. (F) Metatarsus, ventral view. (G) Abdominal apex, ventral view. (H) Anterior portion of head, posterodorsal view. (I) Elytra, dorsal view. Abbreviations: an1 = antennomere 1; ep = epipleuron; es = elytral suture; lb = labrum; lbp = labial palp; $m d=$ mandible; $m s c=$ mesocoxa; mst1-5 = mesotarsomeres 1-5; $\mathrm{mtt} 1-5=$ metatarsomeres 1-5; $\mathrm{mtv}=$ metaventrite; $\operatorname{mxp}=$ maxillary $\mathrm{palp} ; \mathrm{pc}=$ procoxa; $\mathrm{ps}=$ prosternum; $\mathrm{ptb}=$ protibia; $\mathrm{v} 2,5=$ ventrite 2,$5 ; \mathrm{wp}=$ window punctures. Scale bars: $200 \mu \mathrm{m}$. 
Labrum transverse, with tuberculate dorsal surface and anterior margin densely set with setae (Fig. 3A). Antenna (Figs. 2A, 5) short, extending beyond anterior prothoracic margin when posteriorly directed, but not reaching posterior prothoracic margin, 11-segmented and submoniliform, with thin and short setae; antenno-

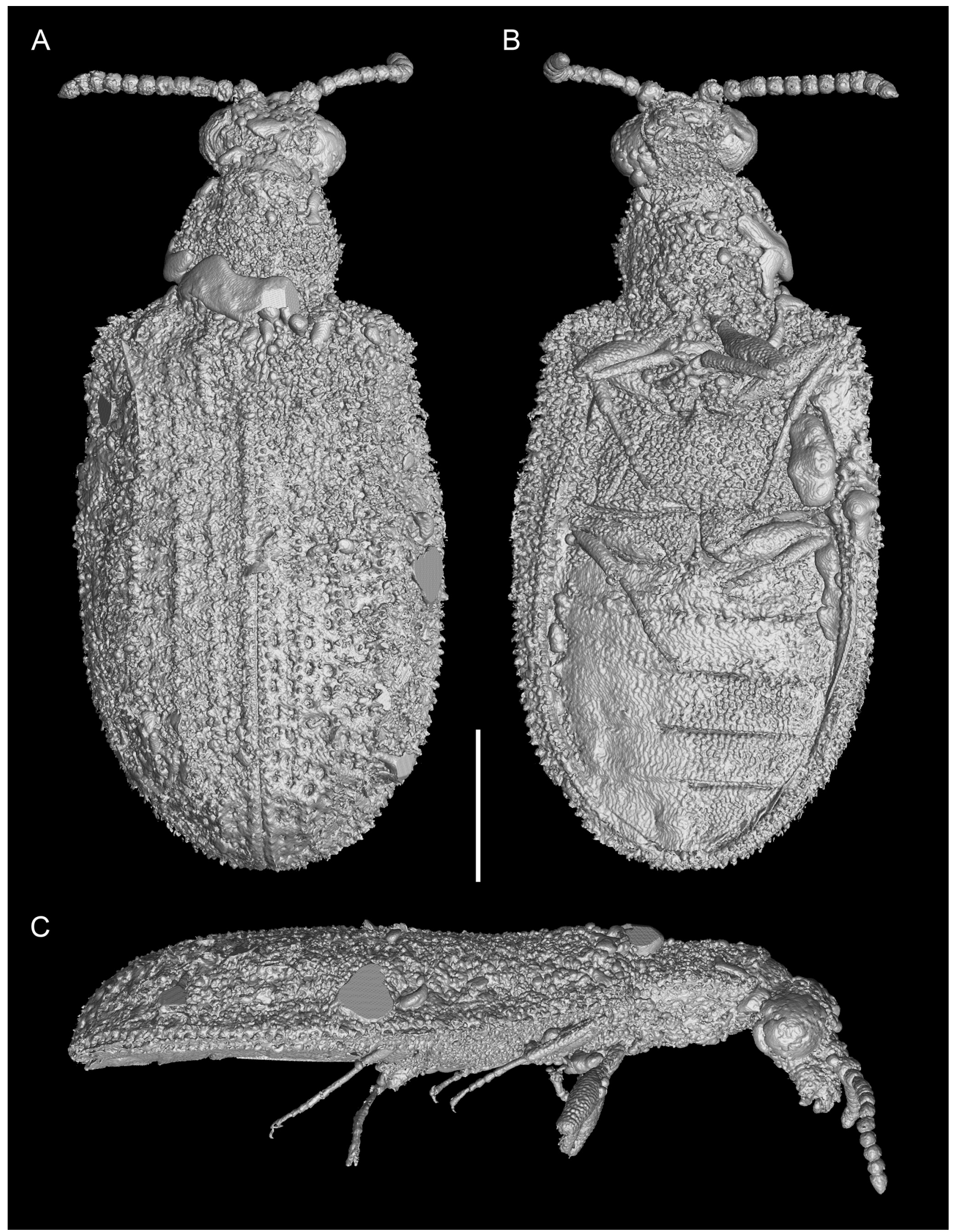

Figure 4. X-ray microtomographic reconstruction of Paraodontomma leptocristatum sp. nov., holotype, NIGP174676. (A) Dorsal view. (B) Ventral view. (C) Lateral view. Scale bar: $1.5 \mathrm{~mm}$. 
mere 1 distinctly wider than other antennomeres, somewhat globular; antennomere 2 distinctly smaller, subquadrate, about as wide as long; antennomere 3 elongate, slightly widening distally; antennomeres 4-10 short, subequal in length; antennomere 11 spindle-shaped, tapering apically. Ratio of antennomere lengths: $~ 3.4$ : $2.3: 3.4: 2.1: 2.1: 1.9: 1.8: 1.8: 1.9: 1.8: 2.9$. Mandibles tridentate with vertically arranged teeth (Fig. 3A). Apical maxillary and labial palpomeres slender, not expanded, with a small cavity near apex (Fig. 3A). Prementum with deep posteromedian pit. Separate mentum present, transverse. Gular sutures not visible.

Pronotal disc (Fig. 2C) anteriorly distinctly narrower than head, posteriorly about as wide, roughly hexagonal, with rounded lateral edges; length about $1.3 \mathrm{~mm}$; maximum width about $1.6 \mathrm{~mm}$; lateral margin strongly serrated; anterolateral and posterolateral pronotal corners angles not projecting and rounded; surface without protuberances or furrows, evenly convex. Pronotal hypomeron narrow, separated from exposed propleuron by slightly curved suture (Fig. 1B). Pleurosternal suture straight (Fig. 1B). Prosternum (Fig. 2D) quadrangular, about as wide as long, very slightly narrowing anteriorly, with slightly convex anterior margin; prosternal process short and narrow, not reaching middle region of procoxae (Fig. 3B). Procoxal cavities contiguous posterior to prosternal process, posteriorly open (Fig. 3B). Procoxae globular to cone-shaped.

Shoulder region pronounced. Mesoscutellar shield not visible (hidden by incrustations). Mesopleura and mesoventrite not clearly visible, partly concealed by legs and partly blurred. Mesocoxal cavities contiguous (Fig. 3C). Mesocoxae similar to procoxae in size and shape. Metanepisternum large, broad anteriorly (Fig. 3E); exposed part of metepimeron moderately sized, visible between elytral epipleura and concave posterolateral metanepisternal edge (Fig. 3E). Metaventrite trapezoidal, strongly narrowing anteriorly, with distinct anteromedian projection; discrimen not visible, probably missing; metakatepisternal suture distinct and complete; metatrochantin distinctly exposed. Metacoxae medially contiguous, transverse, distinctly reaching beyond lateral margin of metaventrite and reaching elytral epipleura laterally; metacoxal plates absent but excavation for metafemur at rest present.

Elytra about $5.5 \mathrm{~mm}$ long, each $1.8 \mathrm{~mm}$ wide in middle region, with setae rooted on tubercles along longitudinal ridges (elytral veins) and small rounded scales on surface (Figs. 3F, 4I). Elytral disc separated into $2 \times 2$ squares by very indistinct longitudinal and transverse ridges (Fig. 6D). Epipleural rim moderately wide, about $1 / 3$ of elytral width anteriorly, evenly narrowing posteriorly, without window punctures (Figs. 2E, 3D). Teeth along outer elytral margins present, but not forming a wave pattern.

Legs (Figs. 2D, E, G, 3F) slender; all three pairs similar in size and shape. Femora robust, widest in middle region. Tibiae about as long as femur, slender. Tarsi 5-segmented, cylindrical; with simple tarsomeres, without distinct brushes of adhesive microtrichia. Length ratio of protarsomeres: $~ 1.8: 1.3: 1.0: 1.0: 1.1$. Length ratio of mesotarsomeres: $~ 5.3: 1.5: 1.4: 1.1: 3.4$. Length ratio of metatarsomeres: $~ 6.7: 2.2: 1.4: 1.2: 3.8$.

Abdomen broad, with five coplanar ventrites, separated by distinct grooves (Fig. $2 \mathrm{H}$ ); ventrites $2-4$ subequal in length; ventrites 5 about 1.3 times as long as ventrite 4, with broadly rounded apex (Fig. 3G). Aedeagus possibly trilobate, as shown in Fig. 6E.

Etymology: The specific name is derived from Greek "leptos", thin, and Latin "crista", crest, referring to the weak ridges on the elytra.

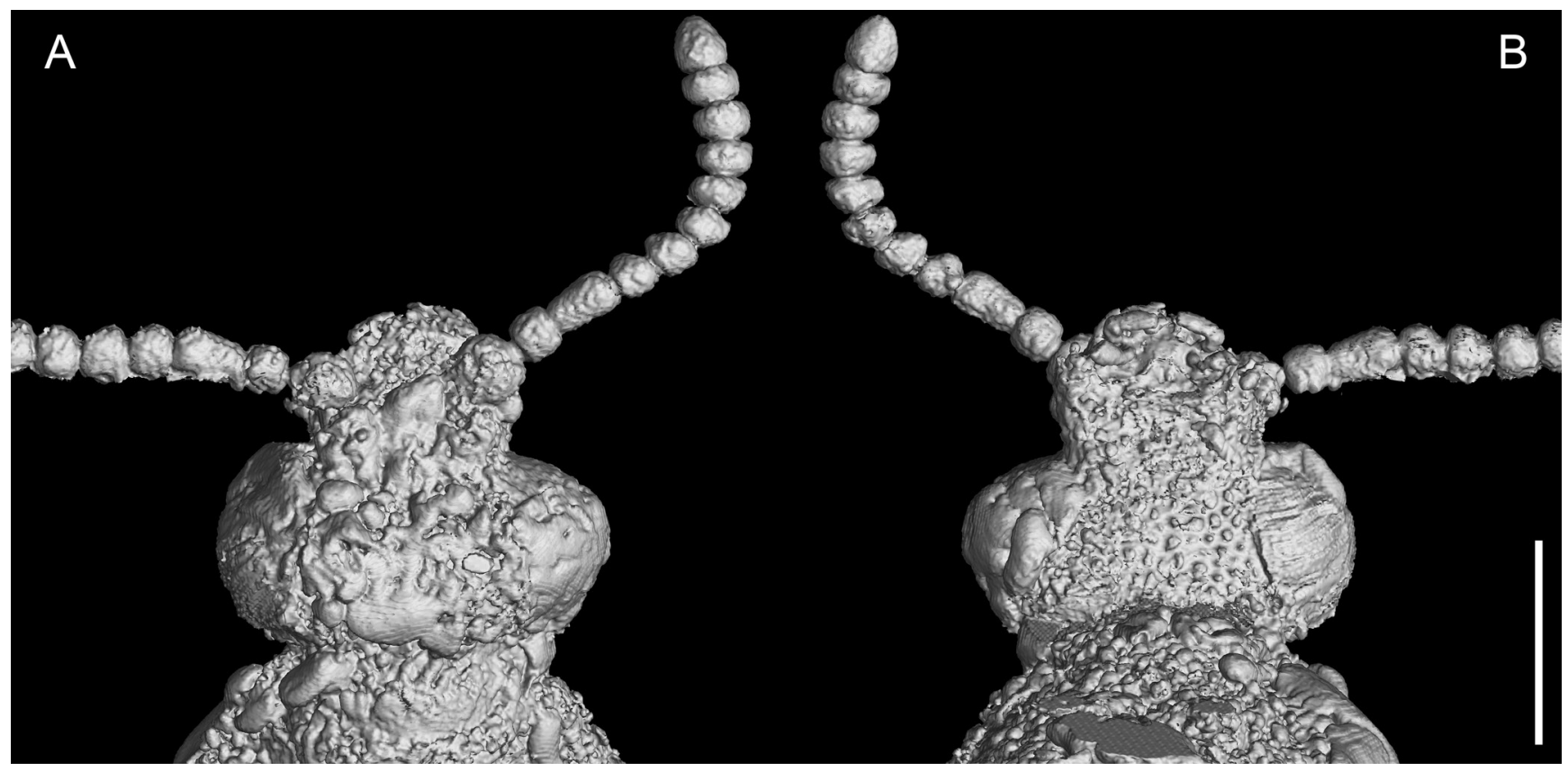

Figure 5. X-ray microtomographic reconstruction of Paraodontomma leptocristatum sp. nov., holotype, NIGP174676. Note that some bubbles were not removed. (A) Head, dorsal view. (B) Head, ventral view. Scale bar: $750 \mu \mathrm{m}$. 

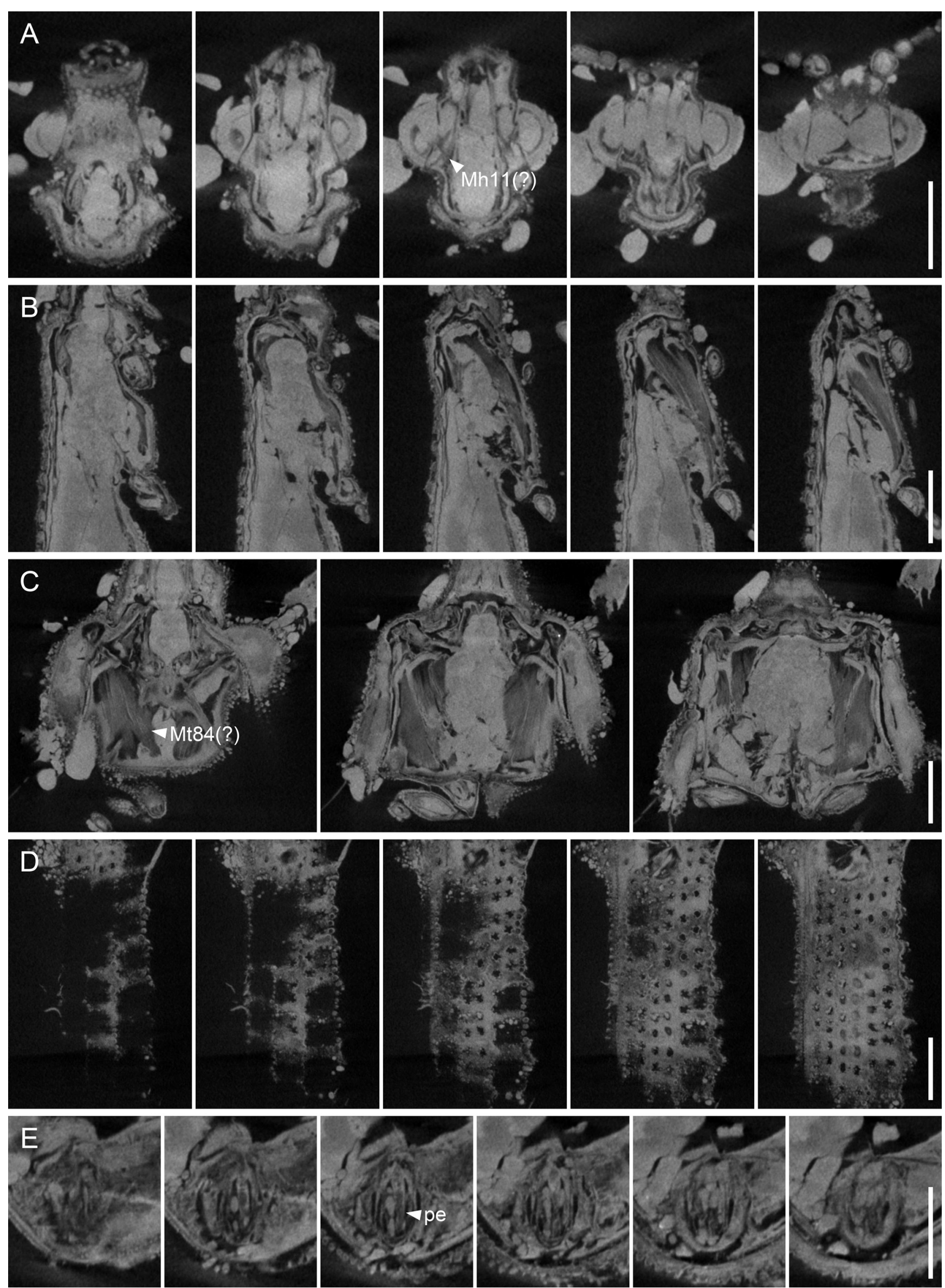

Figure 6. Virtual slices of Paraodontomma leptocristatum sp. nov., holotype, NIGP174676, based on X-ray microtomographic reconstruction. (A) Head, horizontal sections. (B) Metathorax, sagittal sections. (C) Metathorax, subhorizontal sections. (D) Elytron, horizontal sections. (E) Aedeagus, horizontal sections. Abbreviations: Mh11 $=$ Musculus cranio-mandibularis internus; Mt84 = Musculus metanoto-sternalis; pe $=$ penis. Scale bars: $800 \mu \mathrm{m}$. 
The genus name Paraodontomma is an extended version of the genus name Omma Newman, which is a neuter noun in Ancient Greek, meaning eye. Thus, according to Article 30.1.2 of ICZN (1999), the gender of Paraodontomma should also be neuter, rather than feminine as originally claimed by Yamamoto (2017).

\section{DISCUSSION}

Yamamoto (2017) placed Paraodontomma in the tribe Brochocoleini, and further suggested a close relationship between Paraodontomma and Odontomma.
Brochocoleini defined by Tan et al. (2012) is characterized by more than one row of window punctures on the elytral epipleura (e.g., fig. 73 in Hong, 1982; fig. 1 in Liu et al., 2017). However, our new observation revealed that window punctures are absent on the epipleural rim of Paraodontomma (Figs. 2E, 3D, 10F, 11C). Therefore, its tribal placement should be questioned and investigated in the future. Yamamoto (2017) ruled out a close relationship of the extinct genus to fossils with wide epipleural rims assigned to Tetraphalerus, based on the lack of characteristic antennal grooves in Paraodontomma. However, no antennal grooves have been validly observed in any of the Mesozoic "Tetraphalerus" fossils (Li et al., 2021),
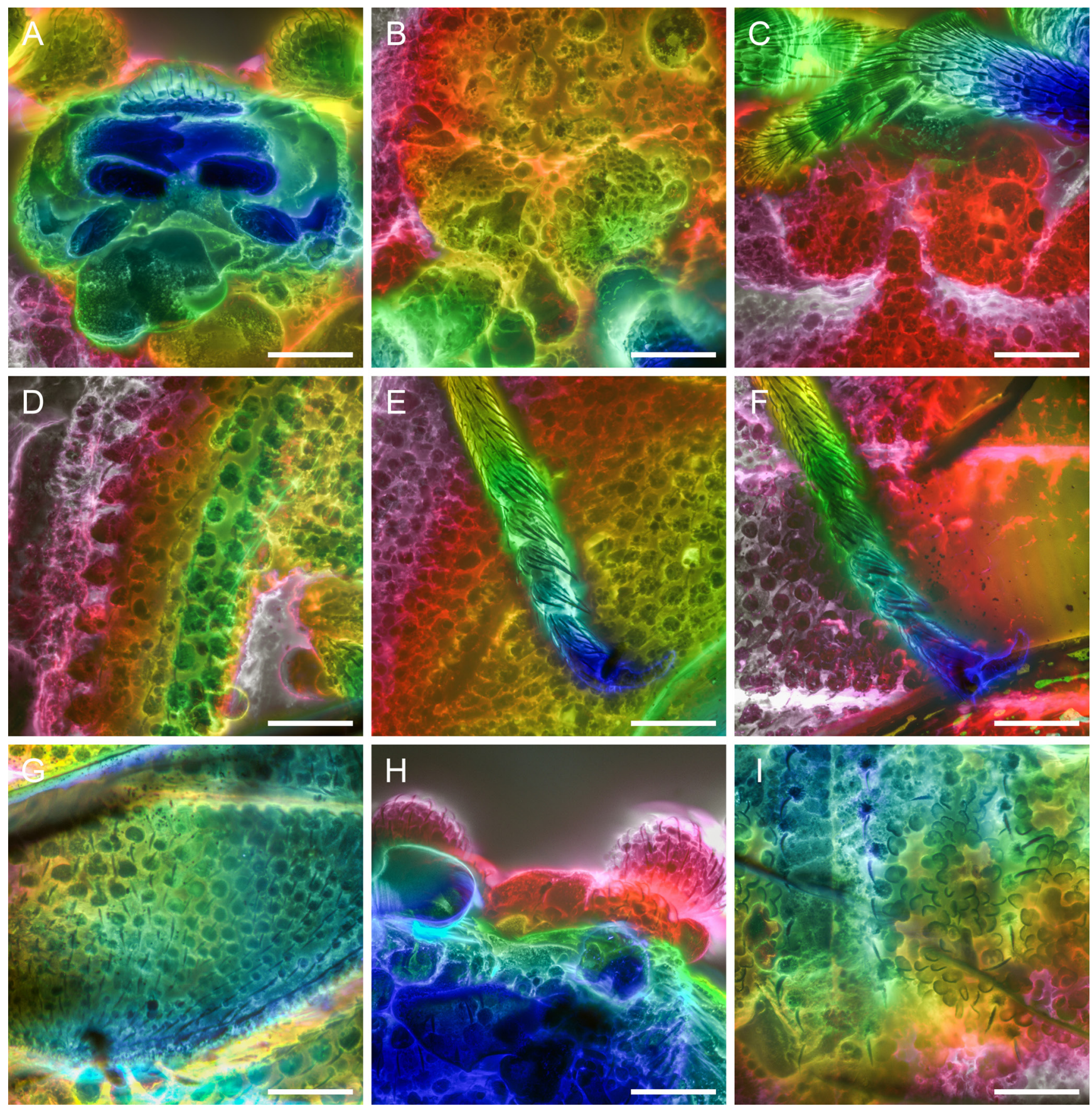

Figure 7. Details of Paraodontomma leptocristatum sp. nov., holotype, NIGP174676, under confocal microscopy, with depth color-coding. (A) Mouthparts, anterior view. (B) Procoxae, ventral view. (C) Mesocoxae, ventral view. (D) Epipleuron, ventral view. (E) Mesotarsus, ventral view. (F) Metatarsus, ventral view. (G) Abdominal apex, ventral view. (H) Anterior portion of head, posterodorsal view. (I) Elytra, dorsal view. Scale bars: $200 \mu \mathrm{m}$. 


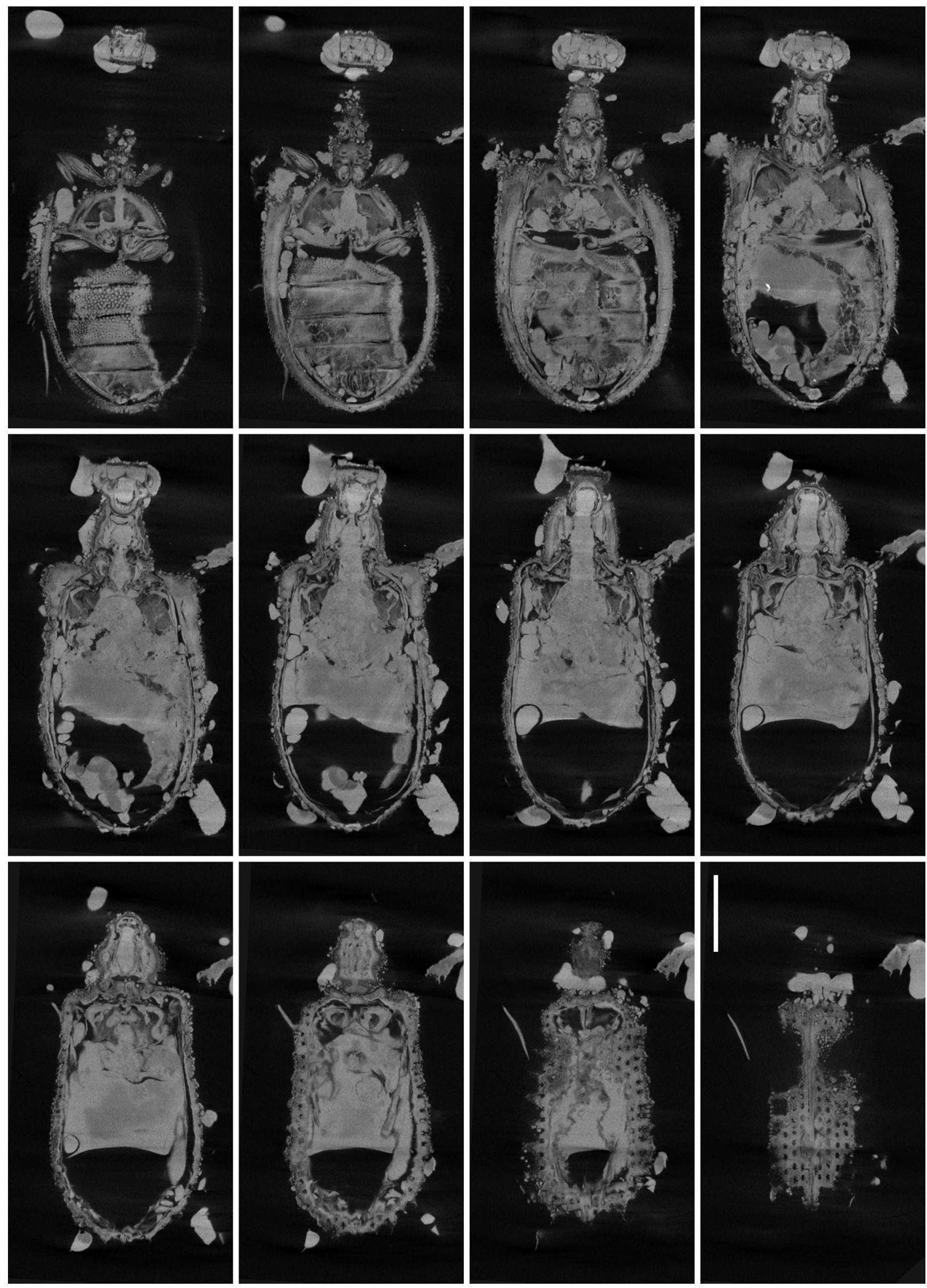

Figure 8. Serial horizontal virtual sections of Paraodontomma leptocristatum sp. nov., holotype, NIGP174676, based on X-ray microtomographic reconstruction. Scale bar: $1.5 \mathrm{~mm}$ 
and many of them have been transferred into genus Allophalerus Kirejtshuk just recently (Kirejtshuk, 2020). The overall shape of some Allophalerus is also similar to Paraodontomma. Therefore, it is ambivalent whether Paraodontomma is closer to Odontomma or Allophalerus based on currently available evidence.

An eye-catching character of Paraodontomma is the presence of transverse ridges on the elytra, which are rarely seen in other Ommatidae and in Cupedidae. The transverse ridges, together with longitudinal ridges (elytral veins), partition the elytra into $2 \times 2$ squares, each containing four window punctures. These transverse ridges are rather prominent in $P$. burmiticum and $P$. szwedoi (fig. 1 in Yamamoto, 2017; figs. 1-2 in Jarzembowski et al., 2018). Although these ridges are quite indistinct in $P$. leptocristatum sp. nov., the $2 \times 2$ squares are still discernable through the micro-CT slices (Fig. 6D). We thus suggest that the transverse ridges on elytra could potentially be an autapomorphy of genus Paraodontomma. The body and elytra of some Cupedidae and Ommatidae are decorated with different scales. Here confocal microscopy revealed a new type of small and rounded scales on the elytra of Paraodontomma (Figs. 3l, 11F). The outer elytral margins of $P$. burmiticum and $P$. szwedoi are armed with somewhat wavily arranged teeth (serration) (Figs. 10F, 11C; fig. 1A in Yamamoto, 2017), while in P. leptocristatum sp. nov. the arrangement of elytral teeth does not form a wave pattern (Figs. 2E, 4D). The head of $P$. burmiticum and $P$. szwedoi is relatively elongate, with the portion in front of eyes longer than the eye (Fig. 10A; fig. 2A in Yamamoto, 2017), while the head of P. leptocristatum sp. nov. is subquadrate, with portion in front of eyes shorter than eye (Fig. 5A).

Under micro-CT, the beetle from Burmese amber often appears as a subhomogenous highly-absorbing solid substrate or a void cavity (e.g., Jałoszyński et al., 2020). In contrast, micro-CT revealed fine internal softparts of our P. leptocristatum specimen (Figs. 6, 8). The striated musculature could be clearly seen in the metathorax of the beetle (Figs. 6B, C), and correspond well to that of ex-
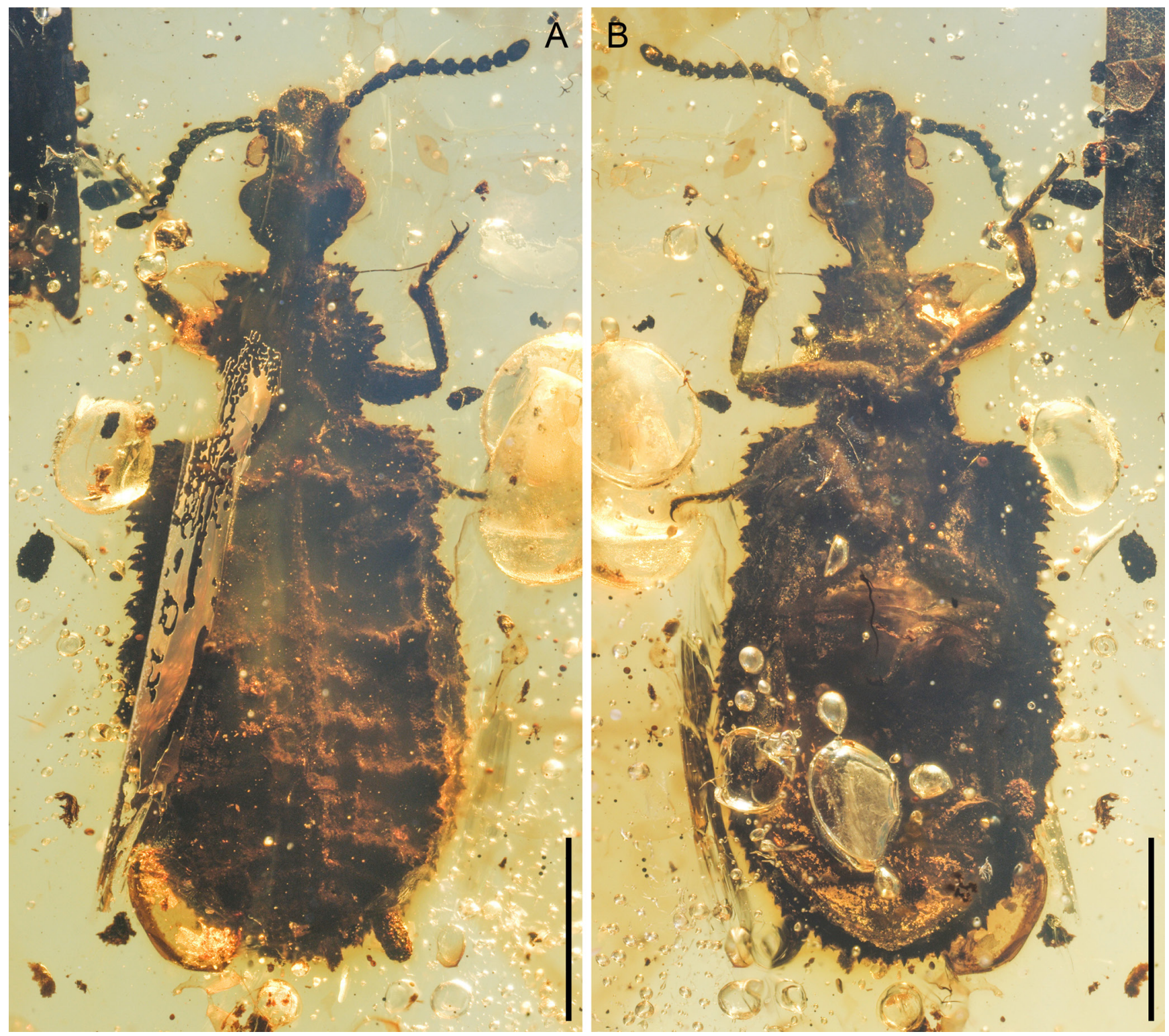

Figure 9. General habitus of Paraodontomma szwedoi, holotype, NIGP169926, under incident light. (A) Dorsal view. (B) Ventral view. Scale bars: 2 mm. 
tant ommatid Tetraphalerus Waterhouse (Friedrich et al., 2009). The muscles showed no apparent shrinkage (similar to Grimaldi et al., 1994; but different from Henwood, 1992b), possibly suggesting a very rapid mummification. Unfortunately, due to the presence of taphonomic artefact and the limitation of resolution, we were only able to identify a few very large muscles. For example, Fig. 6C shows the largest muscle of metathorax, Musculus metanoto-sternalis, with one end attached on metaventrite. This muscle is present in Archostemata as a plesiomorphy but missing in many other groups. The minor muscles with more phylogenetic information were hard to discern in our specimen.

\section{DATA AVAILABILITY}

The original confocal and micro-CT data are available in Zenodo repository (http://doi.org/10.5281/zenodo.4737033).

\section{ACKNOWLEDGMENTS}

We are grateful to Rolf G. Beutel for detailed and helpful discussion, Su-Ping Wu for technical help in micro-CT reconstruction, Yan Fang for technical help in confocal imaging, and Dao-Jun Yuan for help in inspecting the holotype of Paraodontomma szwedoi deposited at NIGP.
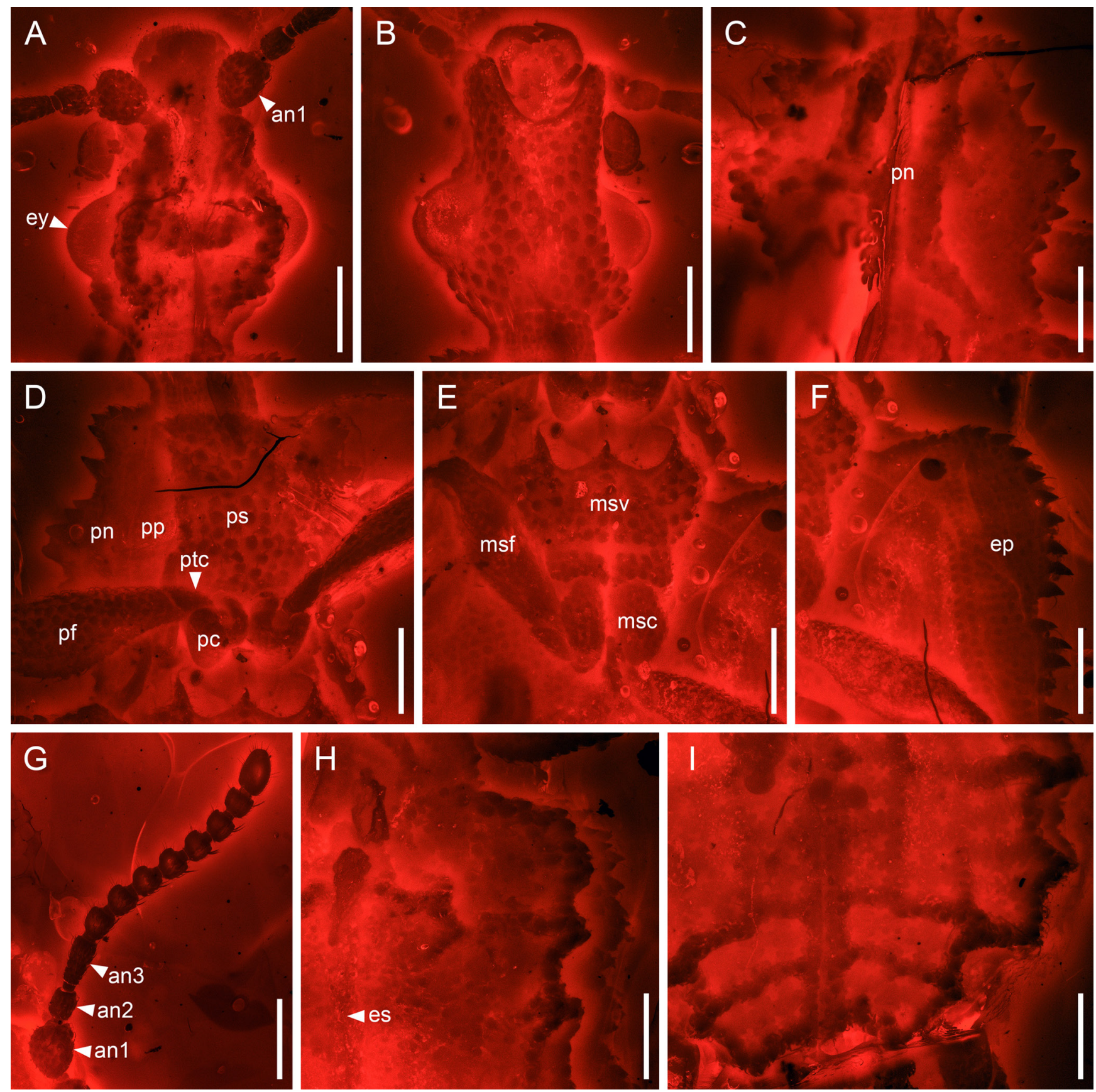

Figure 10. Details of Paraodontomma szwedoi, holotype, NIGP169926, under widefield fluorescence. (A) Head, dorsal view. (B) Head, ventral view. (C) Prothorax, dorsal view. (D) Prothorax, ventral view. (E) Mesothorax, ventral view. (F) Epipleuron, ventral view. (G) Antenna, dorsal view. (H) Elytral base, dorsal view. (I) Elytral apex, dorsal view. Abbreviations: an1-3 = antennomeres 1-3; ep = epipleuron; es = elytral suture; ey = compound eye; $m s c=$ mesocoxa; $m s f=m e s o f e m u r ; ~ m s v=$ mesoventrite; $\mathrm{pc}=$ procoxa; $\mathrm{pf}=$ profemur; $\mathrm{pn}=$ pronotum; $\mathrm{pp}=$ propleuron; $\mathrm{ps}=$ prosternum; $\mathrm{ptb}=$ protibia; $\mathrm{ptc}=$ protrochanter. Scale bars: $500 \mu \mathrm{m}$. 

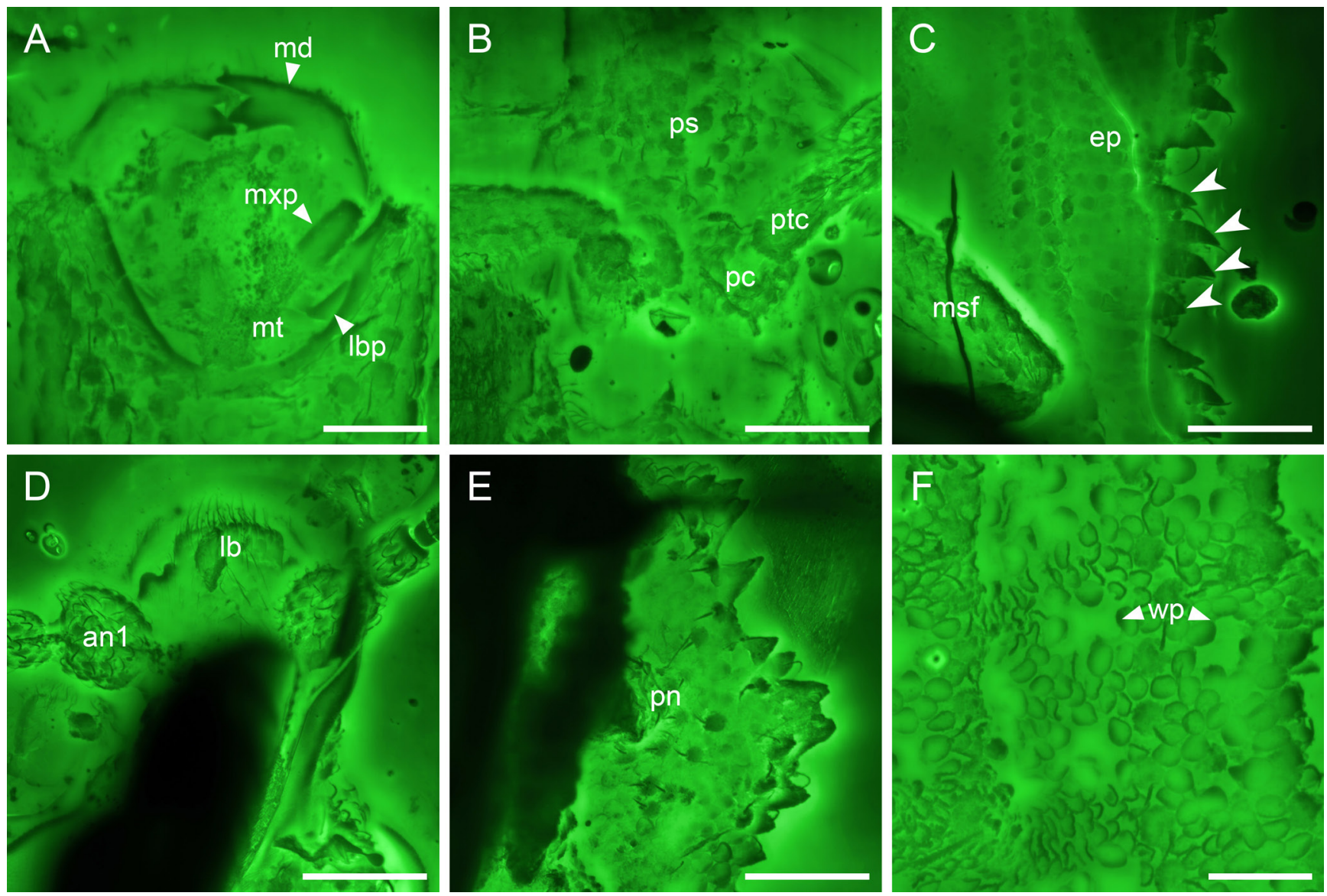

Figure 11. Details of Paraodontomma szwedoi, holotype, NIGP169926, under confocal microscopy. (A) Mouthparts, ventral view. (B) Procoxae, ventral view. (C) Epipleuron, ventral view, showing the wavily arranged teeth along the outer elytral margin (arrowheads). (D) Anterior portion of head, dorsal view. (E) Pronotum, dorsal view. (F) Elytra, dorsal view. Abbreviations: an1 = antennomere 1; ep = epipleuron; lb = labrum; lbp = labial palp; $m d=$ mandible; $m s f=$ mesofemur; $m \times p=$ maxillary palp; $p c=$ procoxa; $p n=$ pronotum; $p s=$ prosternum; $p t c=$ protrochanter; $w p=$ window punctures. Scale bars: $200 \mu m$ in $(A, F), 400 \mu m$ in $(B-E)$.

Financial support was provided by the Strategic Priority Research Program of the Chinese Academy of Sciences (XDB26000000 and XDB18000000), the National Natural Science Foundation of China (41688103), the Second Tibetan Plateau Scientific Expedition and Research project (2019QZKK0706), and Grant-in-Aid for JSPS Fellows (20J00159) from the Japan Society for the Promotion of Science.

\section{AUTHORS' CONTRIBUTIONS}

Y.-D.L. and C.-Y.C. conceived the study. Y.-D.L. acquired and processed the photomicrographs. Y.-D.L. and C.-Y.C. processed the micro-CT data. Y.-D.L. and C.-Y.C. drafted the manuscript, to which S.Y. contributed. All authors commented on the manuscript and gave final approval for publication.

\section{REFERENCES}

Beutel, R.G.; Ge, S.-Q. \& Hörnschemeyer, T. 2008. On the head morphology of Tetraphalerus, the phylogeny of Archostemata and the basal branching events in Coleoptera. Cladistics, 24(3): 270-298. DOI
Escalona, H.E.; Lawrence, J.F. \& Ślipiński, A. 2020. The extant species of the genus Omma Newman and description of Beutelius gen. nov. (Coleoptera: Archostemata: Ommatidae: Ommatinae). Zootaxa, 4728: 547-574. DOI

Friedrich, F.; Farrell, B.D. \& Beutel, R.G. 2009. The thoracic morphology of Archostemata and the relationships of the extant suborders of Coleoptera (Hexapoda). Cladistics, 25: 1-37. D0I

Grimaldi, D.; Bonwich, E.; Delannoy, M. \& Doberstein, S. 1994. Electron microscopic studies of mummified tissues in amber fossils. American Museum Novitates, 3097: 1-31.

Grimaldi, D.A.; Peñalver, E.; Barrón, E.; Herhold, H.W. \& Engel, M.S. 2019. Direct evidence for eudicot pollen-feeding in a Cretaceous stinging wasp (Angiospermae; Hymenoptera, Aculeata) preserved in Burmese amber. Communications Biology, 2: 408. DOl

Henwood, A. 1992a. Exceptional preservation of dipteran flight muscle and the taphonomy of insects in amber. Palaios, 7(2): 203-212.

Henwood, A.A. 1992b. Soft-part preservation of beetles in Tertiary amber from the Dominican Republic. Palaeontology, 35: 901-912.

Hong, Y.-C. 1982. Mesozoic fossil insects of the Jiuquan Basin in Gansu Province. Beijing, Geological Publishing House. 187p. [In Chinese]

Hörnschemeyer, T. \& Beutel, R.G. 2016. Ommatidae Sharp \& Muir, 1912. In: Beutel, R.G. \& Leschen, R.A.B. (Eds.). Handbook of Zoology, Arthropoda: Insecta, Coleoptera, beetles, Vol. 1: morphology and systematics (Archostemata, Adephaga, Myxophaga, Polyphaga partim). 2. ed. Berlin, Walter de Gruyter. p. 52-56. D0I 
International Commission on Zoological Nomenclature (ICZN). 1999. International Code of Zoological Nomenclature. 4. ed. London, International Trust for Zoological Nomenclature. 306p.

Jałoszyński, P.; Luo, X.-Z.; Hammel, J.U.; Yamamoto, S. \& Beutel, R.G. 2020. The mid-Cretaceous †Lepiceratus gen. nov. and the evolution of the relict beetle family Lepiceridae (Insecta: Coleoptera: Myxophaga). Journal of Systematic Palaeontology, 18(3): 1127-1140. D0I

Jarzembowski, E.A.; Wang, B. \& Zheng, D. 2018. A new serrated archaic beetle (Coleoptera: Archostemata) from mid-Cretaceous Burmese amber. Cretaceous Research, 92: 26-30. D0I

Kirejtshuk, A.G. 2020. Taxonomic review of fossil coleopterous families (Insecta, Coleoptera). Suborder Archostemata: superfamilies Coleopseoidea and Cupedoidea. Geosciences, 10: 73. DOI

Li, Y.-D.; Huang, D.-Y. \& Cai, C.-Y. 2021. Revisiting the morphology and systematic placement of the enigmatic Cretaceous ommatid beetle Bukhkalius lindae (Coleoptera: Archostemata: Ommatidae). Papéis Avulsos de Zoologia, 61(28) e20216128. DOI

Liu, Z.; Tan, J.; Slipinski, A.; Jarzembowski, E.A.; Wang, B.; Ren, D. \& Pang, H. 2017. Brochocoleus zhiyuani, a new species of Brochocolein Beetle (Coleoptera: Ommatidae) from the Cretaceous Amber of Myanmar. Annales Zoologici, 67: 79-85. D0I

McKenna, D.D.; Shin, S.; Ahrens, D.; Balke, M.; Beza-Beza, C.; Clarke, D.J.; Donath, A.; Escalona, H.E.; Friedrich, F.; Letsch, H.; Liu, S.; Maddison, D.; Mayer, C.; Misof, B., Murin, P.J.; Niehuis, 0.; Peters, R.S.; Podsiadlowski, L.; Pohl, H.; Scully, E.D.; Yan, E.V.; Zhou, X.; Ślipiński, A. \& Beutel, R.G. 2019. The evolution and genomic basis of beetle diversity. Proceedings of the National Academy of Sciences, USA, 116(49): 24729-24737. DOI
Pohl, H.; Wipfler, B.; Boudinot, B. \& Beutel, R.G. 2021. On the value of Burmese amber for understanding insect evolution: Insights from †Heterobathmilla - an exceptional stem group genus of Strepsiptera (Insecta). Cladistics, 37(2): 211-229. D0I

Pohl, H.; Wipfler, B.; Grimaldi, D.; Beckmann, F. \& Beutel, R.G. 2010. Reconstructing the anatomy of the 42-million-year-old fossil †Mengea tertiaria (Insecta, Strepsiptera). Naturwissenschaften, 97(9):855-859. D0|

Poinar-Jr., G.0. \& Hess, R. 1982. Ultrastructure of 40-million-year-old insect tissue. Science, 215: 1241-1242.

Poinar-Jr., G.0. \& Hess, R. 1985. Preservative qualities of recent and fossil resins: electron micrograph studies on tissue preserved in Baltic amber. Journal of Baltic Studies, 16(3): 222-230.

Ren, D.; Tan, J. \& Ge, S. 2006. New fossil ommatid (Coleoptera: Archostemata: Ommatidae) from Jehol Biota of Western Liaoning, China. Progress in Natural Science, 16(6): 639-543. D0I

Tan, J. \& Ren, D. 2009. Mesozoic archostematan fauna from China. Beijing, Science Press. [In Chinese with English summary]

Tan, J.; Wang, Y.; Ren, D. \& Yang, X. 2012. New fossil species of ommatids (Coleoptera: Archostemata) from the Middle Mesozoic of China illuminating the phylogeny of Ommatidae. BMC Evolutionary Biology, 12: 113. $\underline{\text { DOI }}$

Van de Kamp, T.; Dos Santos Rolo, T.; Baumbach, T. \& Krogmann, L. 2014. Scanning the past-synchrotron X-ray microtomography of fossil wasps in amber. Entomologie heute, 26: 151-160.

Yamamoto, S. 2017. A new genus of Brochocoleini beetle in Upper Cretaceous Burmese amber (Coleoptera: Archostemata: Ommatidae). Cretaceous Research, 76: 34-39. DOI 